\title{
Ant Alduress
}

\section{MENTAL CRIPPLES.}

\section{Delivered before the Winchester Division.}

By GEORGE H. SAVAGE, M.D., F.R.C.P.L., CONBULTING PHYSICIAN AND LECTPRER ON MENTAL DISEASEs, GUY's

A VERY distinguished Commission on the Feeble-minded has recently sent in its report, and there are many sug. gestions in it which in time will develop, but the element of time is a very important one, and $I$ feel that it is the duty of those connected in any way with those suffering from mental disorder to spread their views.

To begin with the earliest cripples : Just as there are children who come into the world wanting in muscular parts or nervous powers to direct the limbs, there are many who enter life wanting the highest brain powers, or, rather, wanting in power of development. I suppose almost any defect of any group of muscles or any limb may incapacitate a child, and so almost any mental defect may throw a human being out of harmony with its surround. ings. I shall not treat of those whom deafness or blindness has outplaced. I constantly see children who are said to be only backward. Yet I know at once that this backwardness depends on some organic want which will never be replaced. I think it is well to recognize the hopelessness of many of these for cure, for harm is done all round when false hopes are raised.

It is well to remember that the weak-minded child is almost always backward in walking as well as in talking, the human attributes of upright walking and talking being absent or backward.

Some of the most troublesome of the cripples are the social or moral ones. I see many children in whom the moral sense seems absent; no power of application, no experience in any way influences them for good, for long at any rate. There are the mental cripples from birth and I hardly know where to begin, for any one of the higher powers or attributes may be deficient or wanting. Among the backward ones who never get into full harmony with their surroundings are some who have no power of attention or concentration.

I fancy power of attention is a late acquirement, and certainly it is one want of which probably most of my audience know as a sign of nervous weakness due to mental strain or nervous fatigue. There are children who never appear able to learn; there are some who pore over books, yet are not instructed thereby; they remain in the lower classes of schools, and often are not bad children but dullards, and will remain such. I knew one boy of this type who, having spent the allotted time at school, was apprenticed first to a shoemaker, then to other trades, but he was found wanting-no occupation was ever found to suit him. Such may become tramps and even rogues, bat often there is nothing really vicious in them.

Another group is wanting in power of appreciating values of things, and I was at first astonished to meet with children to whom anything in the way of figures was a blank. They were as wanting along this line as are the colour blind in recognition of certain colours. No amount of education will cure such. Simple limping rather than crippling is seen in some children, who grow into manhood with complete inability to spell; this is not a very serious matter, but it may ruin the prospects of a clerk.

Next, defects of higher control have to be considered, for in mental crippling there may be loss of power or loss of control. The child with loss of control may be given to rages as an infant, and later to outbreaks of impulsive violence which render him a danger to society; but as such cases rather fall into the wider land of the mentally ansound 1 will pass them by, only noticing that there are such. I must, however, refer to some of those who are more or less incapable of mixing with normal conditions owing to their want of moral sense. That some are organic liars is certain, and these may cause much trouble to themselves and to others, but they have to suffer as a rule for their failings. The organic thief, however, has to be considered from two points of view-the medical and the social. At present he is sent to prison, and after his. discharge returns sooner or later to his old ways. I have experience of such who were collectors of trifles as children, and became skilled thieves later.

The suggestion of the Commission on the Feeble-minded. - that many of the returning criminals should be sent to. colonies and be always under control-is the only reasonable plan, but it is a very large and costly question. The organic thief, in my experience, is sprung almost always from criminal or neurotic stock.

Before leaving the congenital affections of childhood I must refer to some special conditions which lead to. crippling in infancy and childhood. First and foremost the occurrence of fits is noteworthy. I see at Earlswood. idiots whose idiocy dates from infantile convulsions, and. at the Epileptic Colony I see backward children who can only be partially educated, whose weakness came after fits.

I hardly know why, but in my experience there is very serious danger of crippling after measles complicated with lung affection, or after any disease which for a time interferes with healthy respiration, and it is certain that this fact has given rise to what I should consider an. overdone fad in reference to adenoids.

It is certain that convulsions or fevers in childhood may arrest development or modify it. I have known a child after a severe illness lose both power of speech and of walking, and these powers have only slowly, and in some cases only partially, recovered.

From childhood we naturally pass to youth, and already you will see that I recognize that the child is the father of the man. The child intellectually crippled rarely regains perfect ability and stability. There are many who are incapable of real growth. Just as there are dwarfs in mankind and small plants in the vegetable kingdom, so there are moral and intellectual dwarfs. In Central Africa such might appear only as normal pigmies, but here they are out of all relationship to their surroundings.

Physical giants may be mental dwarfs. I saw a powerful youth-and he is only a specimen of manyapparently overgrown muscularly, whose father thought. he might have made a splendid knight errant, but that he was out of place in the twentieth century. There is, in fact, a group of overgrown youths who have all the same type-long, lazy, and self-satisfied, not necessarily depraved but easily falling into evil ways. Of course such cases had better be recognized early as beings who will walk, perhaps, freely in unconventional surroundings but. will trip in society.

I have known the sons of distinguished fathers who have been sent to public schools, and have managed somehow to get through the vears there; later they have been placed in offices or have been sent to read for learned professions. They have not in any way caused. social harm, and, though their parents recognized that they were not brilliant, they did not see that they were generally weak. They failed at their examinations, and their masters returned them as useless for their professions. I have known such sent to most of the. colonies; but these colonies have now got fully to. recognize this class of emigrant and to look upon them as undesirable. Yet, though crippled for higher life, they may be quite useful hewers of wood and drawers of water. I know the son of a distinguished man who is now quite happy as conductor of a 'bus in a colony. This does not. seem a high result of a university career; but, any way, it is better than doing harm or doing nothing. I may say that to send such youths to colonies, without taking the utmost care as to where they are going and that they are under some supervision and direction, is a selfish way of getting rid of responsibility. The number of orange growers, ranchers, and ostrich farmers I have known return to this country as failures is alarming. In Englard similar lads are set to poultry or even dog farming; some, of course, under direction survive or even prosper, but. more fail.

Another type is represented by the clever schoolboy who gains a scholarship at a public school, and who is encouraged to overwork. He gets a scholarship at a university, and for a time all goes well; but he slowly gets run down, suffers from dyspepsia and sleeplessness, gradually power of application is lost, he becomes more 
and more self-centred and hypochondriacal, and at the same time not infrequently he cepases to have any real feeling of his social duties and responsibilities. He is organized selfishness. Such I have seen pass gradually into what I would call mental paralysis.

Another somewbat similar type is that in which a first attack of insanity has changed the whole mental horizon, so that the objects in life seem altered. The girl who was a cheerful companionable person now becomes isolated, neglecting her old friends and making no new ones. Gradually she gets inclined to suspect her neighbours of avoiding her, and from this delusions arise; a fresh attack of acute mental disorder follows which causes further destruction of mind, and the end is dementia, or chronic delusional insanity.

After an attack of insanity permanent mental weakness may occur, or some special line may be marked as that of weakness. I have known an honest woman who after an attack of insanity became dishonest, and had to be classed as a kleptomaniac. A good many persons after mental illness have become intemperate or drug takers, and the friends blame the doctors. The busy active housewife may cease to be a housekeeper, and there are cases in which immorality, and eventually divorce, have followed changes due to mental disease.

A group of cases which I described under the term of "marital incompatibility" includes many such cases, and I may venture to give a sketch of one of the same.

A woman of middle age has a nervous breakdown about the menopause. She recovers, but is no longer the same person. Her servants will not remain with her. She is jealous of her husband and no longer keeps her social position. She falls out with her neighbours, and in many cases makes life with her intolerable, both to husband and children. I regret to say that some of these cases never again are able to walk in harmony.

Besides change of character and defect of ability following attacks of mental disorder, one has to recognize the tendency to frequent breaking down. I fear to compare such cases with those of loose cartilages would seem far fetched, yet they are both untrustworthy as far as strain is concerned. Any way, one of the most common beliefs is that any one who has been once insane is very likely again to become so. There is truth in the belief, but fortunately there are many exceptions; yet we have among the mental cripples to remember those whose weakness is instability.

The next great group which interests me is the cripples who result from other bodily disease. Just as here there are cripples who are weak from congenital defect, while there are others who are unfit as the result of accident or injury, so there are similar mental cripples resulting from general disease. I at times chaff my surgical friends on surgical successes when a useless limb is retained, which to the non-surgical mind would have been better away; so I see certain results of treatment of the insane in which so-called cure is limited in its utility.

Take a concrete example to demonstrate what I mean. A well-educated man, a graduate in arts of a provincial university, became a Nonconformist minister. $\mathrm{He}$ was capable, but belonged to unstable stock. He married, and had fair health; but anxiety and an attack of influenza brought on an attack of mental disorder, which necessitated his being sent to an asylum. After a short attack of mania he recovered, and returned to his work, but he was no longer the eloquent extempore preacher he had been. $\mathrm{He}$ felt his defects, worried, and later had another attack of insanity. He again was discharged "cured," but now he was unfit for his profession, and took a post as a clerk. This only lasted for a time; another attack of mania reduced him to the level of a messenger, and thus from the higher position he fell to one of pure or simple mechanical duty, and the end will be permanent inability.

I regret to say that there are very many examples of similar loss of mental power after bodily or mental illnesses. It is well to recognize that the malady is not always recognized as a nervous one. I have known persons mentally and morally changed after rheumatic fever, after typhoid, and other diseases. I used to think that any disorder associated with a high state of fever was specially dangerous.

I fancy there are cripples in this home (Sir William Treloar's Cripples' Home, Alton) who may have suffered at the hands of inexperienced bonesetters, but I have to say that though bonesetters are a dangerous class, yet one may learn from one's enemies. I have recognized in myself that an adhesion about a joint may be forcibly and painfully but usefully broken down when passive movements have failed; and it is certain that in the cases in which there was apparent mental palsy, some deep impression, some moral shock, has started healthy movement again. I fear I cannot recommend such treatment, but I have to record the fact of its occasional utility.

And now to the conclusion and moral, if there is one, of this rather wide and discursive paper. There are many feeble-minded persons who are at present not sufficiently safeguarded. They need homes, not asylums, and probably farm-colony-like homes will be the best. Next, after attacks of mental disorder, either partial defects of mind or morals may occur, due to the tyranny of the organization, or permanent instability may arise. Lastly, we have fully to recognize that in the high state of conventional civilization in which we are the cripple can never unaided make his way in the world.

\section{TUBERCULOSIS IN LIMEWORKERS.}

\section{By W. J. BURNS SELKIRK, M.A., M.D.EdIN}

THE action of calcium and its salts has of late engaged much attention. Experiments have been artificially performed to determine points bearing upon the action. I desire to draw attention to some of Nature's work on the subject, which seems to be curiously overlooked. I refer to cases where, by reason of the conditions of work or living, relatively large quantities of calcium have been regularly taken into the body during long periods of time. These cases are those of persons who have to work in an atmosphere laden with the fine dust of hydrate and oxide of calcium. Those that have come under my notice are the workers in connexion with limekilns and some parts of cement works. The members of communities supplied with very hard water are also worthy of consideration in this connexion.

My attention was drawn some years ago to the remarkably good health enjoyed by workers in limekilns round Edinburgh, particularly of those well on in years who had been working for a large part of their lives in an atmosphere laden with lime dust. At some of the kilns the labour is casual, and such labour I leave out of account.

Inquiries made among the workers themselves, of managers of works, of old inhabitants of the district, and medical men in the neighbourhood of limekilns, resulted in an agreement of opinion that workers in limekilns enjoyed more than average good health. In particular it was agreed that as a class they are exceptionally free from bronchitis. This being so, I wondered how they stood regarding phthisis, and, on inquiry, I found its incidence apparently nil. I do not say it is absolutely so, but I could not find a case, nor could I hear of one; nor could such persons as I asked-workers, managers, etc.-tell me of a worker in the limekilns having died of phthisis or consumption. At the Warren Cement Works, Hartlepool, where a considerable amount of lime is inhaled and swallowed by those about the works, I found an equally high standard of health and a similar consensus of opinion as to freedom from consumption and bronchitis.

I use the term "consumption," as it was among the laity that most of my inquiries were made, and I refer to bronchitis because manifestations of tuberculosis of the lungs are frequently regarded among the working classes as bronchitis.

I propose, then, the following question: Are those who inhale and swallow much lime abnormally free from tuberculosis of the lungs? Inquiry by those who have it in their power could determine this, and it would be very interesting to hear the opinion of other medical men whe are or have been associated with workers in lime. The growth of the bacillus in a medium containing, say, calcium hydrate, could also be usefully investigated.

The medicinal administration of lime salts in tuberculosis is, of course, not at all recent. For instance, Warburton Begbie highly recommends calcium chloride for glands in the neck, and for diarrhoea with chronic 